\title{
A Study on the Subjectivity of Medical Disputes Perceived by Nursing Students
}

\author{
Sunyoung Jang \\ Department of Nursing, Hanseo University \\ 46 Hanseol Ro, Haemi-myun, Seosan-si, Chungcheongnam-do, 369-709, Korea \\ sjang@hanseo.ac.kr
}

\begin{abstract}
The aim of this study is to identify the subjectivity for the categorization of medical disputes with whom nursing students using $Q$ Methodology. A total of 14 nursing students, with clinical training experience at hospitals, were asked to classify 29 statements on the perception. The collected data was analyzed through QUANL PC Program. In this study, the types of clinical practice were categorized into 3 types: 'medical personnel-centered perception type', 'medical dispute reduction measures-focused type', 'patient-centered perception type'. This study has provided the baseline data for education and counseling program development for nursing students who start clinical practice.
\end{abstract}

Keywords: Medical dispute, Nursing student, Subjectivity, Q-methodology, Nurse

\section{Introduction}

\subsection{Necessity of study}

With the enforcement of the national health insurance in 1989, the improvement of living standard by economic development, and the increase of national interest in health, the use of medical service was also rapidly increased. Despite the provision of high-quality medical service based on the overall development of medical technology and medical personnel's constant efforts, the medical disputes that started to be raised from the middle of 1980, is continuously increasing [1].

Such various side effects caused by the increase of medical disputes are regarded as an important social problem, and they have negative effects on the parties directly-involved in disputes such as patients and medical personnel, and even other members of society. On top of injury or loss of life experienced by victims of medical malpractice and pains experienced by their families as the causes for medical disputes [2], once the medical disputes are led to lawsuits as they could not reach an agreement or solution, the participation in lawsuits increases the social cost and medical expenses, and eventually, the burden is shifted onto patients [3]. In the position of medical personnel, to prevent malpractice or misdiagnosis, they perform overtreatment, defensive treatment, or withdrawn treatment while avoiding emergency medical care. Also, due to the avoidance of treatment subjects with high risk or high possibility of medical disputes, the unbalanced supply and demand of medical personnel and the distortion of healthcare delivery system could occur. Eventually, this phenomenon could be led to a threat to national health and distrust in medical personnel and medical system [1][3].

Article history:

Received (December 28, 2020), Review Result (January 29, 2021), Accepted (April 4, 2021) 
Nurses take the largest portion in the field of the public health and are the core human resources who contact patients most frequently. They should provide high level of nursing services to patients within the limited time frame under the circumstances of the rapidly changing public health sector [4]. The subjectivity of nurses' perception in the field of public health greatly influences their nursing services. Therefore, it is important to find out the perceptions of the nurses and the nursing students.

Studies regarding nurses' perception on medical disputes are not easy to find. Qmethodology is based on the perspectives of the behaving persons rather than researchers and makes it possible to structurally understand the characteristics of individual types of subjectivity [5]. Since the perception of medical disputes is subjective and unique experiences, it is appropriate to use the Q-methodology to find out the types of nurses' perceptions of medical disputes.

Therefore, this study is intended to find out the subjectivity structure of nurses' perception of medical disputes and use it as the underlying material for development of education program for nursing students which is differentiated based on the characteristics of each type of perception of medical disputes.

\subsection{Purpose of study}

The objectives of this study are to provide information about nursing students handling the patients of medical disputes, and also to provide the basic data for presenting the strategies of education for nursing students, by examining the types of subjective perception of medical disputes and the characteristics of each type targeting nursing students, with the application of Q-methodology. For this, the concrete objectives of this study are as follows.

(1) The nursing students' subjective perception of medical disputes is categorized.

(2) The characteristics of nursing students' perception of medical disputes in each type are analyzed and described.

\section{Method of study}

\subsection{Design of study}

After considering the literature, media data, and preceding researches on medical disputes to achieve the objectives of this study, this study finds the subjectivity showing the types of subjective perception of medical disputes targeting nursing students who have experienced medical disputes.

\section{2. $Q$ population and $Q$ sample selection}

To extract comprehensive statements of medical disputes focusing on the current nursing students, the Q-population was drawn through the consideration of domestic/foreign-relevant literature, open-ended questionnaire, and individual in-depth interview. After drawing about 200 Q-populations through this process, total about 100 Q-populations were extracted by integrating the collected literature through the consideration of domestic/foreign-relevant literature. After going through the procedure of reviewing and modifying the extracted Qpopulations of this study, total 34 samples with high discrimination were selected.

\subsection{Design of study}


As a qualitative research emphasizing the individual inertia focusing on differences in intraindividual semanticity or importance instead of interindividual differences, the Qmethodology is based on the small sample doctrine meaning that the characteristics are not clearly revealed if the P-sample gets larger and many people are concentrated on a single factor [6]. As the P-samples, this study selected total 14 nursing students who voluntarily agreed on the participation in this study after fully explaining the objectives of this study to them.

\subsection{Classification and data analysis method}

The Q-classification process is the process in which each individual of research subjects selected as P-samples makes voluntary definition of medical dispute by classifying the statements of Q-samples in the forced normal distribution method [7]. The data was collected from 14 nursing students of $\mathrm{OO}$ university by using the Q-cards. Most of the research subjects took about 30-45 minutes to complete the Q-classification. In the distribution of Q-samples, the research subjects classified the statements selected as Q-samples into from strong affirmation to strong negation according to the importance of their own opinions. The statements of medical disputes(Q1) were classified on the basis of 12-point scale. After that, in relation to the statements classified into both extremes, the further interview with the subjects were conducted. The Q-factor analysis used the Principal Component Factor Analysis(varimax). The classification of types was selected by considering the total explained variance and results produced by variously inputting the number of factors based on the Eigen value 1.0 or up. Regarding the collected data, this study changed the transformed score (1-12 points) given to the forced-distribution cards of Q-sample distribution table, into score. By coding the given transformed score in the order of Q-sample number, it was treated with the principal component factor analysis by the QUANL PC Program. The data was analyzed by using the QUANL pc program [8][9].

\subsection{Ethical considerations for the subject}

Before starting the research, the researcher asked the subjects for their voluntary consent, and then explained to them that it could be stopped anytime during the research. In order to respect the subjects' rights, and also to guarantee their privacy and confidentiality of personal information, all the information collected by this study went through the Q-sorting by treating and coding it anonymously in the whole data analysis processes.

\section{Result of study}

\subsection{Structure of Q-type}

In the results of Q-factor analysis on the nursing students' subjectivity of medical disputes using the QUANL pc program, there were total three types.

\subsection{Analysis of individual types}

Medical Personnel-Centered Perception Type: Total five subjects belonged to Type1. The subjects of Type1 showed strong affirmation to statements like 'There should a bill that could solve medical disputes in case of medical malpractice. $(Z=1.78)$ ', 'The medical sincerity of medical personnel has influences on the medical malpractice. $(\mathrm{Z}=1.51)$ ', and 'The medical disputes suppress the occurrence of medical malpractice. $(Z=1.43)$ ' [Table 1]. In Type1, the 
subject with the highest factor weight was No.9(1.6129), and the statements obtaining the most affirmation were No.2 and No.20.

In the characteristics of Type1, they perceive medical disputes in the position of medical personnel, and also regard them as medical personnel's responsibility. They said that the sincerity of medical personnel would influence medical malpractice, which would be directly led to medical disputes. Also, according to them, despite some weaknesses, the medical disputes have some strengths such as decrease of medical malpractice by making medical personnel pay attention to their service, and getting a consent to the provision of procedure and test after providing sufficient explanation. Therefore, Type1 was named 'medical personnelcentered perception type'.

Medical Dispute Reduction Measures-Focused Type: Total five subjects belonged to Type2. The subjects of Type 2 showed strong affirmation to statements like 'The installation of CCTV in operating room could decrease medical disputes. $(Z=1.66)$ ', 'The results of medical disputes could be different depending on the severity of disorder in victims. $(Z=1.55)$ ', and 'There should a bill that could solve medical disputes in case of medical malpractice. $(Z=1.52)$ '[Table 1]. In Type2, the subject with the highest factor weight was No.11(1.4241), and the statements obtaining the most affirmation were No.29 and No.8.

In the characteristics of Type2, they think that the measures for reducing medical disputes gradually increasing should be considered individually and socially. They said that the installation of CCTV in operating room and the establishment of bill and institution for solving medical disputes could reduce medical disputes that would be more increasing in the future. They said that the medical personnel's efforts would not be good enough to solve the increase of medical disputes, so there should be interest and support in the social level. Therefore, Type 2 was named 'medical dispute reduction measures-focused type'.

Patient-Centered Perception Type: Total four subjects belonged to Type3. The subjects of Type 3 showed strong affirmation to statements like 'The results of medical disputes could be different depending on the severity of disorder in victims. $(Z=2.15)$ ', 'The immediate emergency measures by medical personnel could reduce medical disputes. $(Z=1.94)$ ', and 'There should be a permanent task force that could rationally mediate disputes that could occur in case of medical malpractice. ( $\mathrm{Z}=1.55)$ 'Table 2]. In Type3, the subject with the highest factor weight was No.7(1.8888), and the statements obtaining the most affirmation were No.8 and No.25.

According to them, the medical malpractice could happen in the process of treating patients, and the post-treatment is important though. They thought that the medical personnel's emergency measures and continuous observation of patients' condition could prevent medical disputes, and additionally, there should be policy-level support such as mediation organization after disputes. Therefore, Type3 was named 'patient-centered perception type'.

Table 1. Q-statements on medical disputes and Z-scores per factor $(\mathrm{N}=14)$

\begin{tabular}{|c|c|c|c|c|}
\hline Factor & No & Description & Mean (SD) & Z-score \\
\hline \multirow{2}{*}{$\begin{array}{c}\text { Factor 1 } \\
(\mathrm{N}=5)\end{array}$} & 20 & $\begin{array}{c}\text { There should a bill that could solve medical } \\
\text { disputes in case of medical malpractice. }\end{array}$ & $7.00(2.000)$ & 1.78 \\
\cline { 2 - 5 } & 7 & $\begin{array}{c}\text { The medical sincerity of medical personnel has } \\
\text { influences on the medical malpractice. }\end{array}$ & $7.00(1.871)$ & 1.51 \\
\cline { 2 - 5 } & $2 \begin{array}{c}\text { The medical disputes suppress the occurrence of } \\
\text { medical malpractice. }\end{array}$ & $6.80(1.095)$ & 1.43 \\
\hline
\end{tabular}




\begin{tabular}{|c|c|c|c|c|}
\hline & 29 & $\begin{array}{l}\text { The installation of CCTV in operating room could } \\
\text { decrease medical disputes. }\end{array}$ & $1.80(0.837)$ & -2.13 \\
\hline & 26 & $\begin{array}{l}\text { When the level of medical science gets higher, the } \\
\text { medical disputes will increase. }\end{array}$ & $3.60(1.517)$ & -1.29 \\
\hline & 22 & $\begin{array}{l}\text { When the level of medical service is higher, the } \\
\text { medical disputes decrease. }\end{array}$ & $4.00((2.550)$ & -1.26 \\
\hline \multirow{6}{*}{$\begin{array}{l}\text { Factor } 2 \\
(\mathrm{~N}=5)\end{array}$} & 29 & $\begin{array}{c}\text { The installation of CCTV in operating room could } \\
\text { decrease medical disputes. }\end{array}$ & $7.00(1.414)$ & 1.66 \\
\hline & 8 & $\begin{array}{l}\text { The results of medical disputes could be different } \\
\text { depending on the severity of disorder in victims. }\end{array}$ & $6.80(1.924)$ & 1.55 \\
\hline & 2 & $\begin{array}{l}\text { There should a bill that could solve medical } \\
\text { disputes in case of medical malpractice. }\end{array}$ & $6.80(2.775)$ & 1.52 \\
\hline & 9 & $\begin{array}{l}\text { The medical personnel subject to medical disputes } \\
\text { are highly possible to commit medical malpractice } \\
\text { in the future. }\end{array}$ & $2.20(1.304)$ & -2.09 \\
\hline & 4 & $\begin{array}{l}\text { The medical dispute is a method to relieve victims } \\
\text { of medical malpractice. }\end{array}$ & $2.60(1.342)$ & -1.90 \\
\hline & 24 & $\begin{array}{l}\text { The concrete history taking and physical } \\
\text { examination could reduce medical disputes. }\end{array}$ & $3.40(1.342)$ & -1.35 \\
\hline \multirow{6}{*}{$\begin{array}{l}\text { Factor } 3 \\
(\mathrm{~N}=4)\end{array}$} & 8 & $\begin{array}{l}\text { The results of medical disputes could be different } \\
\text { depending on the severity of disorder in victims. }\end{array}$ & $7.50(1.291)$ & 2.15 \\
\hline & 25 & $\begin{array}{l}\text { The immediate emergency measures by medical } \\
\text { personnel could reduce medical disputes. }\end{array}$ & $7.00(1.826)$ & 1.94 \\
\hline & 1 & $\begin{array}{l}\text { There should be a permanent task force that could } \\
\text { rationally mediate disputes that could occur in case } \\
\text { of medical malpractice. }\end{array}$ & $7.25(0.957)$ & 1.55 \\
\hline & 9 & $\begin{array}{l}\text { The medical personnel subject to medical disputes } \\
\text { are highly possible to commit medical malpractice } \\
\text { in the future. }\end{array}$ & $3.00(2.708)$ & -1.91 \\
\hline & 21 & $\begin{array}{l}\text { One of the causes for medical disputes is the } \\
\text { maldistributed selection of treatment methods to } \\
\text { doctors. }\end{array}$ & $3.50(2.082)$ & -1.61 \\
\hline & 20 & $\begin{array}{l}\text { The medical sincerity of medical personnel has } \\
\text { influences on the medical malpractice. }\end{array}$ & $3.50(2.380)$ & -1.52 \\
\hline
\end{tabular}

\section{Discussion}

In the results of this study, the types of subjectivity of medical disputes perceived by nursing students were Type 1- 'medical personnel-centered perception type', Type 2- 'medical dispute reduction measures-focused type', and Type 3- 'patient-centered perception type', and this study aims to discuss the characteristics of each type.

In this study, Type1 was 'medical personnel-centered perception type'. As preservice nurses, they sought for the measures for preventing or solving medical disputes focusing on the position of nurse. They thought that the medical personnel should do their best not to have any medical malpractice in hospital, and the nurses should play important roles.

Type 2 was 'medical dispute reduction measures-focused type'. They think that there should be the social preventive measures or management for the occurrence of medical disputes. According to them, if it is unavoidable to have medical disputes regardless of scale or degree, 
the national/social policies or regulations should be rationally and clearly established to be helpful to medical personnel and patients. They said that the victims of medical disputes would be the relative week in Korean society, so it would be necessary to seek for the measures for protecting them.

Type 3 was 'patient-centered perception type'. They think that the efforts to maintain and enhance the patients' health status are important after the occurrence of medical malpractice or medical disputes. They also thought that raising the medical disputes in the position of patients would be their natural rights rather than giving burden to medical institution or medical personnel, which could contribute to the reduction of medical malpractice and the medical development in the future.

This research on the subjectivity would be helpful for changing the perception of medical disputes in our society. Moreover, this study could be utilized as the basic data for the development of differentiated educational program by presenting the subjective structure of medical disputes perceived by nursing students as preservice medical personnel and also the characteristics of each type.

However, this study targeted a single university and did not consider the factors having effects on the perception of medical disputes for the selection of subjects, so it is limited to generalize the results of this study. Thus, there should be a follow-up research to additionally verify the types by composing the Q-sample with various backgrounds.

\section{Conclusion}

This study aimed to establish the basic data necessary for presenting the changes in the perception of medical disputes and the approach to nurses based on the subjective data analyzing the nursing students' subjective perception of medical disputes, by applying the Qmethodology. In the results of this study, total three factors were drawn. The types of medical disputes perceived by nursing students were 'medical personnel-centered perception type', 'medical dispute reduction measures-focused type', and 'patient-centered perception type'.

This study provided the basic data for establishing the improvement measures for attitude and perception of medical disputes in the future by categorizing the nursing students' subjectivity of medical disputes. This study analyzed the types of perception of medical disputes targeting nursing students and then verified the characteristics of each type, so there should be an effort to develop educational programs considering the characteristics of each type. This study also suggests an additional research on the analysis of types by producing the samples considering various factors, and a qualitative research to verify various factors having effects on the care of patients subject to medical disputes.

\section{References}

[1] B. K. Eun, "A study on factors influencing psychological rehabilitation of the disabled laborers from industrial accident," M.S. thesis, Ewha Women's University, Seoul, (1999)

[2] J. C. Lee, H. Y. Min, K. H. Kim, and H. N. Kim, "Factors associated with the malpractice settlement cost between doctors and patients in Korea," Korean Association of Health and Medical Sociology, vol.28, pp.171196, (2010)

[3] E. Shin, "A study for analysis of the current status of medical disputes and the characteristics by medical department (centered on the data of 2006 Korea Consumer Agency)," M.S. thesis, Yonsei University, Seoul, (2007)

[4] S. Dyess and C. Parker, "Transition support for the newly licensed nurse: A programme that made a difference," Journal of Nursing Management, vol.20, pp.615-623 (2012) DOI: 10.1111/j.1365-2834.2012.01330.x 
[5] W. Stephenson, "Q-methodology, "Interbehavioral psychology and quantum theory," Psychol Record, vol.32, pp.235-248 (1982)

[6] S. M. Whang, S. W. You, J. Y. Kim, and R. G. Kim, "Consumer types and cultural consumption characteristics of Korean society: Who spends for what reasons?” Journal of Human Subjectivity, vol.13, pp.25-39 (2006)

[7] H. Lee, S. Jang, and M. Wang, "A study on patients' perceptions of patient safety (Q method)," Asia-pacific Journal of Law, Politics and Administration, vol.1, no.2, pp.1-6, (2017) DOI: 10.21742/AJLPA.2017.1.2.01

[8] M. Wang, S. Kim, and S. Jang, "Study of subjectivity on death in Korean elderly," International Journal of Elderly Welfare Promotion and Management, vol.2, no.2, pp.37-42, (2018) DOI: 10.21742/IJEWPM.2018.2.2.07

[9] S. Jang, "The subjectivity for open adoption of nursing students," International Journal of Advanced Nursing Education and Research, vol.3, no.1, pp.59-64 (2018) DOI: 10.21742/IJANER.2018.3.1.10 
A Study on the Subjectivity of Medical Disputes Perceived by Nursing Students

This page is empty by intention. 